

\title{
Anorectal manometry in children with defecation disorders BSPGHAN Motility Working Group consensus statement
}

\author{
Eleni Athanasakos $^{1}$ (D) | Stewart Cleeve ${ }^{1}$ | Nikhil Thapar ${ }^{2,3}$ | Keith Lindley ${ }^{4}$ | \\ Steve Perring ${ }^{5}$ (D) | Hannah Cronin ${ }^{4}$ | Osvaldo Borrelli ${ }^{4}$ | Mohamed Mutalib ${ }^{6}$ (D)
}

\author{
${ }^{1}$ Paediatric Surgery, Royal London Hospital, \\ London, UK \\ ${ }^{2}$ Gastroenterology, Great Ormond Street \\ Hospital, London, UK \\ ${ }^{3}$ UCL Great Ormond Street Institute of Child \\ Health Library, London, UK \\ ${ }^{4}$ Department of Paediatric \\ Gastroenterology, Division of Paediatric \\ Neurogastroenterology and Motility, Great \\ Ormond Street Hospital for Children NHS \\ Trust, London, UK \\ ${ }^{5}$ Medical Physics, Poole Hospital NHS Trust, \\ Poole, UK \\ ${ }^{6}$ Paediatric Gastroenterology, Evelina \\ London Children's Hospital, London, UK

\section{Correspondence} \\ Eleni Athanasakos, Children's Anorectal \\ Physiology Service, The Royal London \\ Hospital, Whitechapel Road, London E1 \\ 1BB, UK. \\ Email: eleni.athanasakos@nhs.net
}

\begin{abstract}
Defecatory disorders in children, including chronic constipation (CC) and fecal incontinence (FI), are common conditions worldwide and have a significant impact on children, their families, and the healthcare system. Anorectal manometry (ARM) and high-resolution anorectal manometry (HRAM) are relatively novel tools for the assessment of anal sphincter function and rectal sensation and have contributed significantly to improving the understanding of the anorectum as a functional unit. ARM has been recognized as the investigation of choice for adults with symptoms of defecation disorders, including fecal incontinence (FI), evacuation difficulties, and constipation. Although it is the gold standard tool in adults, it has yet to be formally accepted as a standardized diagnostic tool in the pediatric age, with limited knowledge regarding indications, protocol, and normal values. ARM/HRAM is slowly becoming recognized among pediatricians, but given that there are currently no agreed guidelines there is a risk that will lead to diversity in practice. The British Society of Paediatric Gastroenterology, Hepatology and Nutrition (BSPGHAN)-Motility Working Group (MWG) therefore has taken the opportunity to provide guidance on the use of ARM/HRAM in children with $\mathrm{CC}$ and/or FI.
\end{abstract}

\section{KEYWORDS}

anal sphincter, anorectal function, faecal incontinence, high -resolution anorectal manometry, paediatric chronic constipation

\section{1 | INTRODUCTION}

Chronic constipation (CC) with or without fecal incontinence (FI) is a common condition in children with a worldwide prevalence of up to $29.6 \% .^{1-6}$ It has a significant impact on children, their families, and healthcare systems. Although typically CC is managed in outpatient and community clinics, children with CC are increasingly presenting to emergency departments (ED). ${ }^{7} \mathrm{FI}$ is particularly distressing and is associated with poor quality of life (QoL), reduced school attendance, and social interaction. ${ }^{8,9}$ Children with CC report a worse QoL compared with children affected by IBD and gastroesophageal reflux (GORD). ${ }^{10}$ Most of the published guidelines are directed toward the management of functional constipation and provide a framework and general guidance., ${ }^{11,12}$ but there remains wide variation in the use of diagnostic tools and management strategies for children with $\mathrm{CC}$ with or without FI.

Fecal incontinence has an estimated worldwide prevalence of up to $8 \% .{ }^{13}$ and in most children is secondary to constipation, ${ }^{14}$ but in approximately $20 \%{ }^{15}$ it is associated with conditions such as non-retentive fecal incontinence (NFI). ${ }^{16}$ Pelvic floor dyssynergia, which This is an open access article under the terms of the Creative Commons Attribution License, which permits use, distribution and reproduction in any medium, provided the original work is properly cited.

(c) 2020 The Authors. Neurogastroenterology \& Motility published by John Wiley \& Sons, Ltd. 
describes poor coordination between pelvic floor muscles and abdominal wall muscles during defecation, can also lead to $\mathrm{FI}$ and will require different management strategies. ${ }^{17}$

In children with $\mathrm{FI}$ secondary to $\mathrm{CC}$, the majority will have functional constipation ${ }^{18}$ but up to $5 \%$ are affected by other medical conditions that lead to delayed transit or sphincter dysfunction such as Hirschsprung's disease, ${ }^{19}$ spina bifida, ${ }^{20}$ or anorectal malformation. ${ }^{14}$ In these groups of children, the use of anorectal manometry (ARM) to study anorectal physiology is valuable to understand the underlying pathophysiology and direct treatments to best achieve satisfactory outcomes and alleviate the distress of FI.

Anorectal manometry is considered the gold standard tool for the assessment of anorectal function in adults for over a century, ${ }^{21}$ with high-resolution ARM (HRAM) slowly gaining momentum. ${ }^{22}$ In adult practice, ARM/HRAM is used to guide management bowel symptoms such as CC, defecation disorders, and FI. ${ }^{23,24}$ However, in pediatrics, rectal manometry has yet to be fully implemented as part of routine investigations of children presenting with similar symptoms.

Anorectal physiology testing in children was historically performed under sedation ${ }^{25,26}$ either because of the young age, the likelihood of them being uncooperative, or simply because it has been perceived as an invasive procedure. ${ }^{27}$ ARM in an awake child has been used in isolated conditions (eg, Hirschsprung's disease) ${ }^{26,28-33}$ with limited use of the novel HRAM. ${ }^{34,35}$

From the available evidence of the use of ARM/HRAM in pediatrics, it is clear that issues around the type of equipment, methodology, and protocol remain unstandardized. This may significantly impact interpretation and comparison of results. The use of high-resolution manometry has provided a paradigm shift in manometry testing of the upper gastrointestinal (GI) tract, $^{36}$ replacing traditional manometry as the gold standard investigation of esophageal function. Similarly, HRAM is able to visualize the anorectum as a dynamic structure during test maneuvers (such as squeeze, push, and enhanced squeeze), ${ }^{37}$ which can lead to better appreciation of normal physiology and furthermore enhance our understanding of the pathophysiology of defecation in children. Yet, despite the benefits of using HRAM, it is uptake for the assessment of anorectal function, has been less enthusiastic.

An ANMS-NASPGHAN consensus document on anorectal and colonic manometry in children was published in $2016 .{ }^{27}$ It was the first document to aim at standardization of practice and provided a platform upon which this group has built on. Although ARM/HRAM is slowly becoming recognized among pediatricians but given that there are currently no agreed guidelines, there is a risk that will lead to diversity in practice. The British Society of Paediatric Gastroenterology, Hepatology and Nutrition (BSPGHAN)-Motility Working Group (MWG) therefore has taken the opportunity to provide guidance on the use of ARM/HRAM in children with CC and/or FI.

\section{2 | METHODS}

The authors conducted structured literature search using PubMed between 2004 and 2018 for literature published in English using all possible combinations of the following keywords: (a) "anorectal," "rectoanal," "malformat*," "Hirschsprung*," "dyssynerg*," "constipat*"; (b) "manometr*," "physiolog*"; and (c) "paediatric*," "pediatric*," "child*," "neonat*." The working group then met face to face in series of meetings to discuss and answer the following questions:

1. What are the indications for performing ARM in children

2. Should ARM in children be performed awake or under sedation

3. How should children be prepared for ARM

4. What catheter should be used to perform ARM in children

5. How to perform ARM in children

6. How should ARM in children be analyzed and reported

Studies were included if they reported on any aspect of ARM/ HRAM in children relevant to the working group aim and purpose. Studies were screened using the principle of the GRADE strength of evidence and grouped into high, moderate, low, and very low qualities. As all the evidence was in low and very low-quality groups, hence, the recommendations were weak and are based on the group consensus. The working group consensus was reached after evaluating the available literature through personal qualitative opinion of the individual members of the working group combined with current pediatric practice (as represented by the members of the MWG) and expert opinion.

The group then voted anonymously on each of the recommendations using a 9-point scale where 1 is strongly disagree and 9 is strongly agree. Consensus was reached if more than $80 \%$ of the working group members voted $6,7,8$, or 9 . A consensus was reached for all of the questions.

\subsection{What are the indications for performing ARM in children}

Anorectal manometry is used in children to measure sphincter function, recto-anal inhibitory reflex (RAIR), anorectal coordination, and rectal sensation. ARM is useful in identifying whether children can differentiate between a squeeze and push and recognize both their endurance squeeze to prevent $\mathrm{Fl}$ and their ability to understanding when they need to defecate.

TABLE 1 Awake versus under sedation anorectal manometry

\begin{tabular}{lcc} 
& Under sedation & Awake \\
\hline Resting pressure (RP) & $\checkmark$ & $\checkmark$ \\
\hline Squeeze pressure (SP) & & $\checkmark$ \\
\hline Enhanced squeeze (ES) & & $\checkmark$ \\
\hline Cough reflex (CR) & $\checkmark$ & $\checkmark$ \\
\hline Push & & $\checkmark$ \\
\hline RAIR & & $\checkmark$ \\
\hline Rectal sensation & & $\checkmark$ \\
\hline
\end{tabular}


Recommendation 1: The BSPGHAN motility group recommends that the indications to perform ARM/ HRAM include the following:

- Screening for Hirschsprung's disease-this is the most common and accepted indication for anorectal manometry in children. ${ }^{35,38-40}$ This can be done in the awake child or under general anesthesia.

Voting: 9, 9, 9, 8, 8, 9, 9, 9

- Persisting symptoms of constipation with or without FI unresponsive to standard medical therapy. ${ }^{31,41-43}$

Voting: 9, 9, 9, 9, 9, 9, 9, 9

- Chronic FI (retentive or non-retentive) including fecal urgency. ${ }^{27,44-46}$

Voting: 9, 9, 9, 9, 9, 9, 9, 9

- Evaluation of anorectal functions before and after intervention such as surgery, botulinum toxin injection, and biofeedback. ${ }^{26,47-49}$

Voting: 9, 9, 9, 9, 8, 9, 9, 9

- Evaluation of sphincter function in children with persistent defecation problems following the treatment of congenital abnormalities of the anorectum or organic causes of constipation (eg, anorectal malformation and spinal cord lesions). ${ }^{28,50,51}$

Voting: 9, 9, 9, 9, 9, 9, 9, 9

- Evaluation of sphincter function in children with postHirschsprung's disease surgery.

Voting: 9, 9, 9, 9, 9, 9, 9, 8

- Assessment of children with suspected anal sphincter damage (eg, postanorectal surgery or surgery for spinal cord malformation). ${ }^{19,33}$

Voting: 9, 9, 9, 9, 9, 9, 9, 9

- To assess defecation dynamics including children with suspected dyssynergic defecation. ${ }^{25,46}$

Voting: 9, 9, 9, 9, 9, 9, 9, 9

\subsection{Should ARM in children performed awake or under sedation}

Performing ARM under sedation provides limited physiological measurements as the discrepancy with type of anesthesia and level of sedation used that can interfere with the physiological outcomes. ${ }^{52,53}$ If the ARM procedure is carried out awake, rather than under sedation, more physiological parameters can be obtained (Table 1). It is, however, recognized that is certain circumstances (eg, significant child distress or anxiety, learning difficulties, or in infants with suspected Hirschsprung's disease) ARM can be done under sedation. If sedation is needed, muscle relaxants should be avoided and clarity given to the parents and recipient healthcare professionals with regard to the limited information obtained (essentially limited to resting pressure of the anal sphincter and RAIR). ${ }^{26,54}$
Recommendation 2: The BSPGHAN motility group recommends that

2.1 All patients should be offered to have the ARM/ HRAM procedure performed awake rather than under sedation.

Voting: 9, 9, 7, 9, 9, 9, 9, 9

2.2 Sedation can be used to perform ARM/HRAM where it would not be possible to carry it out awake. ${ }^{26}$ This includes, but is not limited to, significant child distress or anxiety, learning difficulties, or in young infants unable to comply with instructions).

Voting: 9, 9, 7, 9, 9, 9, 9, 9

\subsection{How should children be prepared for ARM}

Patient's preparation is essential to ensure successful completion of the test. The child's developmental status and procedural anxiety should be addressed and accounted for in the preparation before the test date. Involving a play therapist and/or psychologist is considered good practice and is vital in alleviating anxiety or distress about the procedure. ${ }^{55-58}$

Recommendation 3: The BSPGHAN motility group recommends that

1.1 A pretest screening interview be carried out to explain the procedure, identify any special requirement, and plan for the day of the procedure including distraction techniques if required.

Voting: 9, 9, 9, 9, 9, 9, 9, 9

1.2 Informed consent be obtained as a mandatory requirement prior to the procedure.

Voting: 9, 9, 9, 9, 9, 9, 9, 9

1.3 An age-appropriate enema be given to the patient on the day or the evening prior to the day of investigation if the rectum is impacted. Alternatively, a degree of bowel preparation is generally required prior to ARM/ HRAM and children are encouraged to continue their regular laxatives and increase them if necessary.

Voting: 9, 9, 8, 9, 7, 9, 9, 9

\subsection{What catheter should be used to perform ARM in children}

There are two types of manometry systems, water-perfused and solid-state either conventional or high-resolution manometry. In water-perfused, the catheter is formed of multiple lumens that open at different parts of the catheter along its length according 
to catheter design. Water is perfused at a constant flow via a pneumohydraulic pump. External transducers detect the pressure generated by resistance to flow from lumen occlusion. In a solid-state catheter, numerous microtranducers are built into the catheter, so that pressure changes directly influence the transducers to generate electrical signal output. Either can be used for this procedure.

In conventional ARM, catheters usually have fewer sensors, about three to six unidirectional sensors with wider intervals between the sensors. As such, a pull-through technique is recommended to allow accurate location of anal sphincter; this will add extra time to the total duration of the procedure compared with stationary technique used in high resolution. The output of conventional manometry catheters is in line plot. The catheters are durable, robust, and not that expensive.

High-resolution catheters on the other hand have several densely positioned sensors circumferentially across a defined length of the catheter. Up to 36 sensors were manufactured, and they can output either topographic color contour or line plot. The catheters are fragile and expensive but are usually used as stationary examination, hence less time-consuming.

High-resolution manometry system is significantly more expensive compared with conventional manometry. Although HRARM is described as superior to conventional ARM in adults, there is limited pediatric experience comparing the two systems.

Recommendation 4: The BSPGHAN motility group recommends that

Either water-perfused or solid-state catheters can be used for the ARM/HRAM procedure.

Voting: 9, 9, 9, 9, 8, 9, 9, 9

Both conventional resolution and high resolution can provide basic information about anorectal physiology; however, HRAM can provide detailed analysis in color contour plot.

Voting: 9, 9, 9, 9, 9, 9, 9, 9

\subsection{How to perform ARM in children}

Recommendation 5. The BSPGHAN motility group recommends that to perform the ARM/HRAM procedure, the following steps (5.1-5.9) are carried out in sequence. ${ }^{21,22,27,46,59}$

Voting: 7, 8, 9, 9, 9, 9, 9, 9

5.1Children are instructed to defecate if required prior to investigation.

5.2Children are given privacy to get ready and are asked to cover up to maintain dignity. Commercially available clothing to protect dignity can be used.
5.3Once the child is ready in the left lateral position with the knees and hips flexed, the members of the team enter the investigation room. At this stage, if play therapist input is needed, the clinician would give them the required time to prepare with the child.

5.4Prior to catheter insertion, perinatal inspection be carried out together with a digital rectal examination (if possible). These actions are desirable to assess:

- If the anal canal is filled with feces-thus an enema or disimpaction would need to be given

- The general anatomy of the patient

- Skin excoriation

- The ability of the subject to understand the commands "squeeze" and "push."

5.5The catheter is zeroed at the anal verge to calibrate and then lubricated with a manufacturer recommended lubricant.

5.6a. In HRAM, the catheter is inserted into the rectum and pull back slightly until the anal canal is located. Once the anal canal is located, the probe is taped to the buttock cheeks to avoid movement.

5.6. b. If conventional ARM catheter is used, a pull-through is performed and several pull-through is performed to measure anal canal length.

5.7The child is allowed a familiarization period (approximately $3 \mathrm{~min}$ utes) to ensure sufficient reading and the child is comfortable.

5.8The ARM maneuvers are performed in a standard sequence with a 30 seconds of recovery period between each maneuver (Figure 1) which includes $21,22,27,35,46,59$

1. Resting pressure: Anorectal pressures are measured with the patient relaxed, lying still. When required, music or a movie film (of their choice) should be provided to keep them relaxed.

2. Squeeze pressures and endurance squeeze: The child is instructed to squeeze the anal canal as strongly possible for a period of 15-20 seconds-this was repeated twice to ensure the best squeeze. The child should not be distracted at this point to ensure they are focusing on the maneuver, and then, maximum squeeze and endurance squeeze can be calculated.

3. Push (simulated defecation): While still lying in the left lateral position, the child is asked to bear down for 20-30 seconds as if to defecate; in children, we describe this as "like blowing bubbles or a balloon and letting out the poo/wind." The child should not be distracted at this point to ensure they are focusing on the maneuver. This can be repeated as many times needed to ensure they are understanding what is expected of them. Often, it is useful to place your hand on their abdomen to ensure they are doing this correctly (abdomen should be expanded outward).

4. Cough: The patient is asked to cough forcefully once on two occasions

5. Recto-anal inhibitory reflex (RAIR): It is evaluated by rapidly inflating the rectal balloon with 5 - $\mathrm{ml}$ increments in infants and by $10-\mathrm{ml}$ increments in older children. The volume to elicit a 

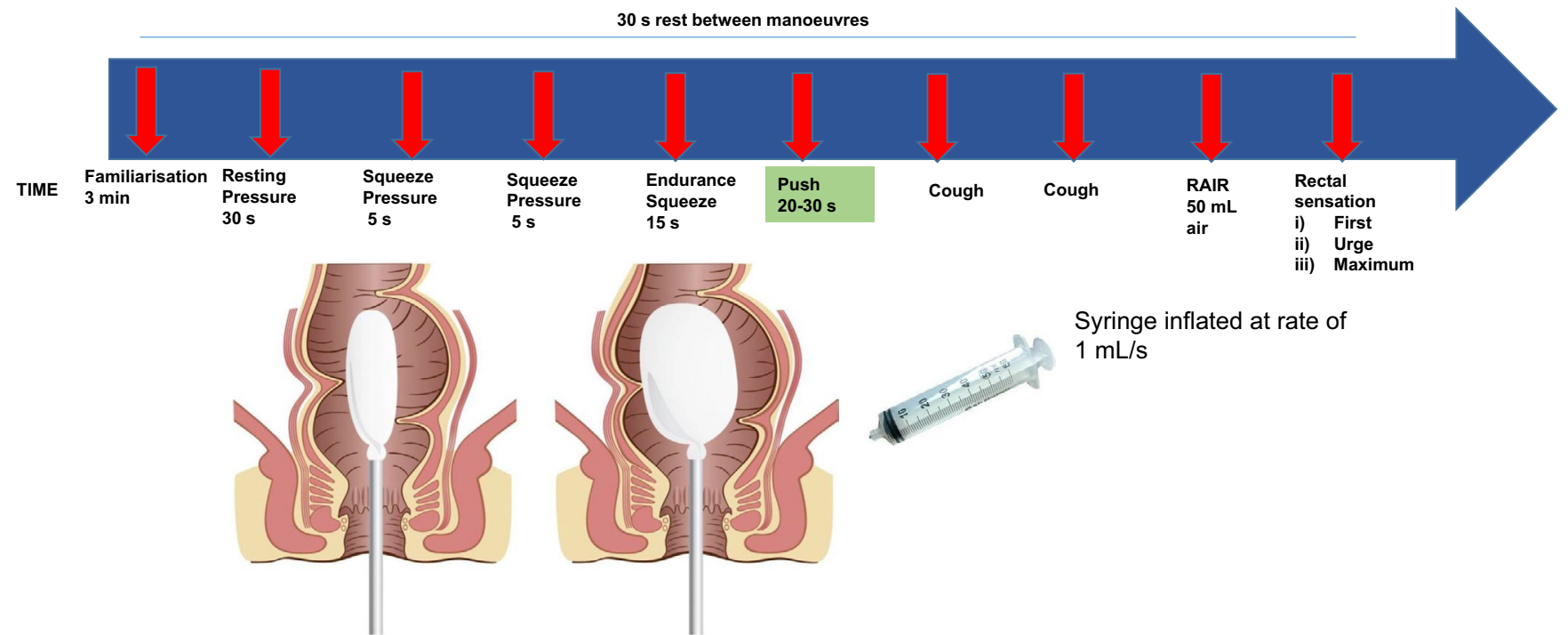

iii) Maximum

Normal values (adults)

First constant eensation: Defaecatory desire volume: Maximum tolerable volume:
$(20-110) \mathrm{mls}$

$(40-200) \mathrm{mls}$

$(75-290) \mathrm{mls}$

FIGURE 1 Pediatric awake high-resolution anorectal manometry protocol (modified from adult practice for pediatric use) ${ }^{17}$

RAIR varies greatly-this is dependent on the size of the rectum, type of catheter size, etc Thus, this needs to be increased until a response is elicited.

6. Rectal sensation: It is assessed by inflating air at $1 \mathrm{ml}$ per second. The child is asked to notify the operator when they:

- first feel anything different (pressure, sensation)

- get an initial urge to defecate

- reach the maximum tolerable volume (when they can no longer hold on and need to open their bowels)

5.9. Once the ARM maneuvers are completed, the catheter is removed and the child allowed to dress.

\subsection{How should ARM in children analyzed and reported}

The report for ARM/HRAM should include a quantitative assessment of different parameters (resting pressure, squeeze pressure, cough reflex, RAIR) and a qualitative assessment of the other parameters (Table 2). ${ }^{21,22,46,59-61}$ For each maneuver period, the anal canal area should be highlighted as an "area of interest" using the e-sleeve box. This allows the software to derive the maximum pressure recorded over this anal length at each point in time. Averages can then be calculated automatically over the duration

TABLE 2 High-resolution anorectal manometry pediatric parameters ${ }^{22}$

\begin{tabular}{|c|c|}
\hline Maneuver & Definition \\
\hline $\begin{array}{l}\text { Functional anal canal } \\
\text { length (FACL) }\end{array}$ & Length of anal canal $(\mathrm{cm})$ in which pressure exceeded rectal pressure by $>5 \mathrm{~mm} \mathrm{Hg}$ \\
\hline $\begin{array}{l}\text { Average anal resting } \\
\text { pressure }\end{array}$ & Average maximum pressure $(\mathrm{mm} \mathrm{Hg})$ over the $\mathrm{FACL}$ during the 30 -s period of rest \\
\hline $\begin{array}{l}\text { Maximum } \\
\text { incremental anal } \\
\text { squeeze pressure }\end{array}$ & $\begin{array}{l}\text { Maximum recorded pressure }(\mathrm{mm} \mathrm{Hg} \text { ) at any point during voluntary squeeze, minus the mean maximum resting pressure } \\
\text { prior to the maneuver (over } 5 \mathrm{~s} \text { ) }\end{array}$ \\
\hline $\begin{array}{l}\text { Average anal } \\
\text { squeeze pressure }\end{array}$ & $\begin{array}{l}\text { Mean maximum pressure }(\mathrm{mm} \mathrm{Hg} \text { ) sustained over the duration of the } 5 \text {-s squeeze maneuver minus the mean maximum } \\
\text { resting pressure prior to the maneuver (over } 5 \mathrm{~s} \text { ) }\end{array}$ \\
\hline $\begin{array}{l}\text { Endurance squeeze } \\
\text { duration }\end{array}$ & $\begin{array}{l}\text { Length in time }(15 \mathrm{~s}) \text { over which a pressure at or above } 50 \% \text { of the highest recorded squeeze pressure was sustained. The } \\
\text { endpoint was determined as the point at which the pressure first dropped below this threshold }\end{array}$ \\
\hline Anal cough pressure & $\begin{array}{l}\text { Highest recorded pressure within the anal canal }(\mathrm{mm} \mathrm{Hg}) \text { at any point during the cough maneuver, minus the maximum } \\
\text { resting pressure prior to the maneuver (over } 5 \mathrm{~s} \text { ) }\end{array}$ \\
\hline $\begin{array}{l}\text { Push-used to } \\
\text { assess defecation } \\
\text { dynamics }\end{array}$ & $\begin{array}{l}\text { Qualitatively analyzed-The use of the color contour plots clearly highlighting coordinated recto-anal events during the } \\
\text { push maneuver }\end{array}$ \\
\hline
\end{tabular}




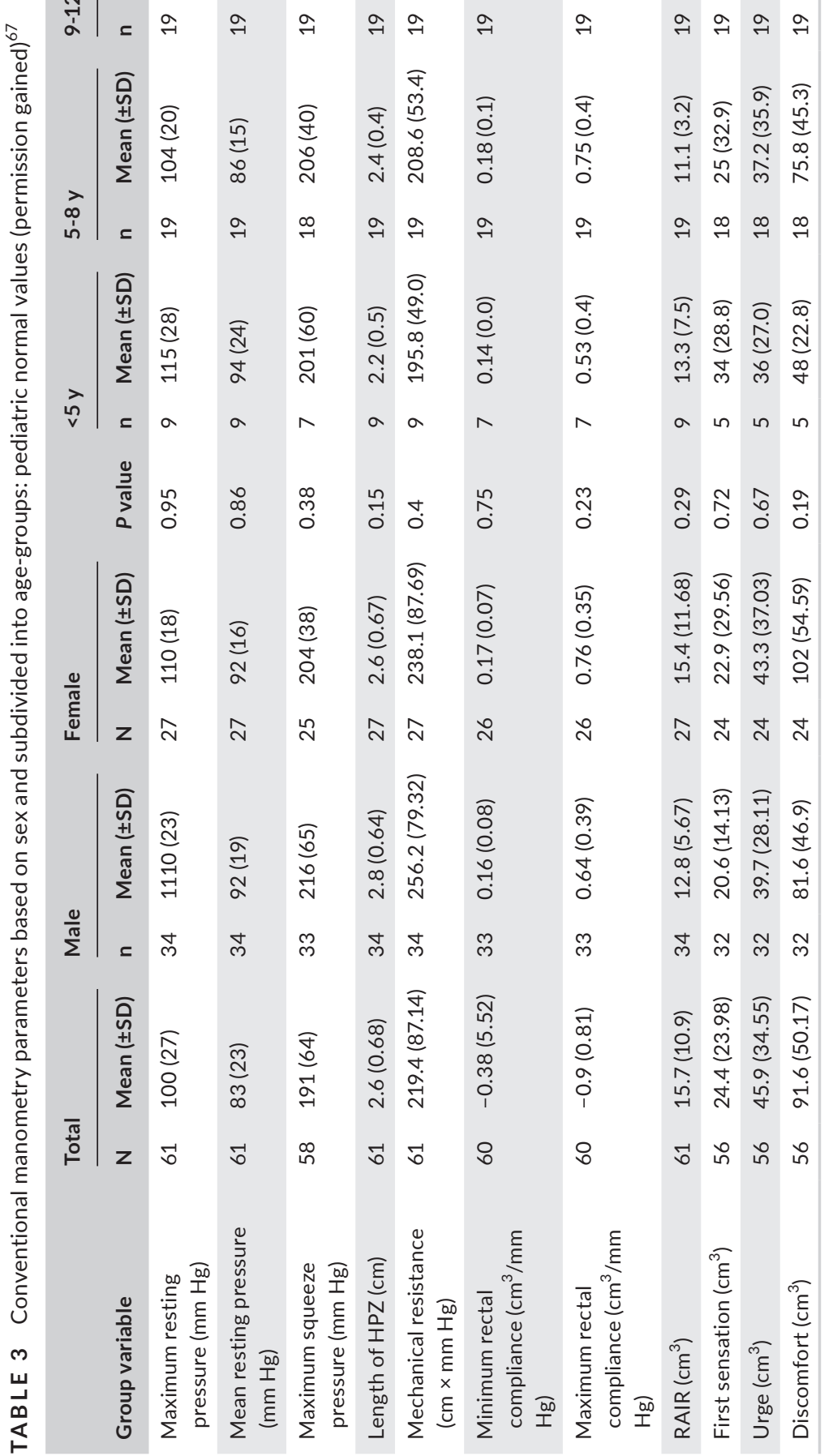


TAB LE 4 Suggested normal values for use of clinical practice ${ }^{22}$

\begin{tabular}{|c|c|c|c|c|c|c|c|c|}
\hline \multirow[b]{2}{*}{ Suggested normal values } & \multicolumn{2}{|c|}{ All females } & \multicolumn{2}{|c|}{ Parous females } & \multicolumn{2}{|c|}{ Nulliparous females } & \multicolumn{2}{|l|}{ Males } \\
\hline & Lower & Upper & Lower & Upper & Lower & Upper & Lower & Upper \\
\hline Functional anal canal length $(\mathrm{cm})$ & 2.3 & 5 & 2.3 & 4.9 & 2.3 & 5.3 & 2.4 & 5.1 \\
\hline $\begin{array}{l}\text { Average anal resting pressure }(\mathrm{mm} \\
\mathrm{Hg})\end{array}$ & 33 & 101 & 31 & 100 & 47 & 110 & 38 & 114 \\
\hline $\begin{array}{l}\text { Maximum absolute anal squeeze } \\
\text { pressure }(\mathrm{mm} \mathrm{Hg})\end{array}$ & 90 & 397 & 86 & 387 & 89 & 447 & 94 & 590 \\
\hline $\begin{array}{l}\text { Maximum incremental anal squeeze } \\
\text { pressure }(\mathrm{mm} \mathrm{Hg})\end{array}$ & 45 & 324 & 43 & 313 & 52 & 352 & 61 & 525 \\
\hline $\begin{array}{l}\text { Average absolute anal squeeze } \\
\text { pressure }(\mathrm{mm} \mathrm{Hg})\end{array}$ & 73 & 314 & 71 & 310 & 74 & 348 & 86 & 430 \\
\hline $\begin{array}{l}\text { Average incremental anal squeeze } \\
\text { pressure }(\mathrm{mm} \mathrm{Hg})\end{array}$ & 29 & 235 & 24 & 232 & 32 & 247 & 40 & 366 \\
\hline Endurance squeeze duration (secs) & 2 & 30 & 3 & 30 & 2 & 30 & 3 & 30 \\
\hline Residual push pressure (mm Hg) & 16 & 88 & 15 & 99 & 16 & 79 & 20 & 93 \\
\hline Push relaxation percentage (mm Hg) & $\mathrm{Oa}$ & 66 & $\mathrm{Oa}$ & 64 & $\mathrm{Oa}$ & 81 & $\mathrm{Oa}$ & 51 \\
\hline Peak rectal push pressure (mm Hg) & 21 & 122 & 22 & 129 & 19 & 144 & 20 & 132 \\
\hline $\begin{array}{l}\text { Maximum absolute anal cough } \\
\text { pressure (mm Hg) }\end{array}$ & 82 & 298 & 70 & 276 & 82 & 315 & 109 & 498 \\
\hline $\begin{array}{l}\text { Maximum incremental anal cough } \\
\text { pressure }(\mathrm{mm} \mathrm{Hg})\end{array}$ & 34 & 224 & 35 & 221 & 34 & 230 & 29 & 413 \\
\hline
\end{tabular}

of the maneuver. The variables recorded together with their respective definitions are shown in Table 2. In order to interpret the results to inform clinical an understanding of normal values is needed.

\subsection{Normal values}

One of the principle challenges to adopting HRAM or conventional ARM in children is to establish new normative data sets of an adequate size for recognized measures of anal sphincter function, and to promote standardization of the technique so that results are transferrable between institutions, a problem that has bedeviled traditional practice. At present, there are numerous published data of findings in healthy adults, ${ }^{22,60,62-64}$ with even fewer within pediatrics. ${ }^{35,65-67}$ In the absence of true pediatric normal values, this working group suggest to use adult values for children over the age of 12 years and to adopt the values published by Banasiuk et $\mathrm{al}^{67}$ as it represents the largest pediatric series of children without lower Gl symptoms (Table 3). We acknowledge the different equipment used by this group, as 3D HRAM may not exactly match the results from standard HRAM or conventional ARM, but the study is the largest to date in children. Their inclusion criteria included children without symptoms arising from the lower $\mathrm{Gl}$ tract who underwent manometric evaluation at the Department of Paediatric Gastroenterology and Nutrition, Medical University of Warsaw, Poland. Exclusion criteria were as follows: age younger than 1 year and older than 18 years, history of surgery for anorectal malformations, diagnosis of constipation or fecal soiling established by Rome III criteria, diagnosis of inflammatory bowel diseases or any other type of large bowel inflammation, presence of anal fissure, anal varices, inflammation of the anorectal area, or any other disease that may interfere with the function of the anorectum. The population was divided into age-groups of $<5$ years, 5-8 years, 9-12 years, and older than 12 years. When age appropriate, the group recommend adopting the internationally agreed normal values for healthy adults (Table 4).

Recommendation 6: The BSPGHAN motility group recommends that the report for the ARM/HRAM includes

6.1. Quantitative assessment of different parameters (resting pressure, squeeze pressure, cough reflex, RAIR).

Voting: 9, 9, 9, 9, 9, 9, 9, 9

6.2. Qualitative assessment of the other parameters (Table 2).

Voting: 9, 9, 9, 9, 9, 9, 9, 9

6.3. Comparison of normative values for the parameters. These normative values are currently derived from reference (Banasuik et al), but the motility group recognize that these could be further contributed to/superseded by new studies.

Voting: 9, 9, 8, 7, 9, 9, 9, 9 
TABLE 5 Clinical indications and interpretation of ARM/HRAM parameters

\begin{tabular}{|c|c|c|}
\hline Parameter & Rationale & Outcome and clinical implications \\
\hline $\begin{array}{l}\text { Squeeze and } \\
\text { endurance squeeze }\end{array}$ & $\begin{array}{l}\text { Assessment of anal sphincter contractile } \\
\text { integrity }\end{array}$ & $\begin{array}{l}\text { Low maximum pressure: } \\
\text { Non-compliant/ poor understanding } \\
\text { Disorder of the anal sphincter (neurogenic or myogenic) } \\
\text { Injury } \\
\text { Reduced endurance pressure: } \\
\text { Non-compliant child/ poor understanding } \\
\text { Nerve damage }\end{array}$ \\
\hline Push & $\begin{array}{l}\text { Assessment of coordination (in } \\
\text { conjunction with anal sphincter pressure } \\
\text { (ASP)) }\end{array}$ & $\begin{array}{l}\text { Adequate pressure with high ASP } \\
\text { Type } 1 \text { dyssynergia } \\
\text { Poor push with high ASP } \\
\text { Type } 2 \text { dyssynergia } \\
\text { Adequate pressure with no decrease in ASP } \\
\text { Type } 3 \text { dyssynergia } \\
\text { Poor push with no decrease in ASP } \\
\text { Type } 4 \text { dyssynergia }\end{array}$ \\
\hline Cough & Assessment of sacral reflex arc & $\begin{array}{l}\text { Impaired response } \\
\text { Suggestive of damage to sacral reflex arc }\end{array}$ \\
\hline Rectal sensation & Assessment of rectal sensation & $\begin{array}{l}\text { Help understand children' understanding of different sensation } \\
\text { Generally marker for rectal capacity and compliance, for example, in } \\
\text { children with functional constipation. } \\
\text { Impaired sensation may be seen in neurological disturbances such as } \\
\text { spinal cord disorders }\end{array}$ \\
\hline
\end{tabular}

\section{8 | Rectal manometry in pediatric clinical practice}

Table 5 summarizes the clinical indications of each of ARM/HRAM studied parameters with the clinical interpretation of abnormal results ${ }^{17,68}$

\section{3 | CONCLUSION}

The concept of performing anorectal manometry to gain pathophysiological information was firstly acknowledged by Gowers in $1887 .{ }^{69}$ Since then, we have progressed greatly in terms of experience and technical advances; especially with adults. Yet, there remains

controversy, confusion, and lack of understanding as to when and how HRAM should be performed in children.

It is acknowledged that some center will have different resources allocated to pediatric GI motility services; this consensus is intended as guidance tool to maintain standardization and allow flexibility to accommodate different settings.

ARM and HRAM are becoming the investigation of choice for understanding the pathophysiology of CC with or without FI in children in many institutions. In HRAM, we are able to gain information whether the symptoms are related to sphincter dysfunction, impaired sensation, or pelvic floor dyssynergia. Maneuvers such as "squeeze" and "push" are key elements for rectal evacuation, which can be visualized and assessed. With the increasing use of other modalities to treat constipation in children such 
TABLE 6 Unmet needs and gaps in knowledge

\begin{tabular}{|c|c|}
\hline $\begin{array}{l}\text { Unmet needs and gaps } \\
\text { in knowledge }\end{array}$ & Suggested strategies/ actions to address this \\
\hline $\begin{array}{l}\text { Pediatric normative } \\
\text { values }\end{array}$ & $\begin{array}{l}\text { To study anorectal manometry parameters and assessment } \\
\text { protocols in normal children (underway in at least one center in the } \\
\text { UK) }\end{array}$ \\
\hline $\begin{array}{l}\text { The values of each of } \\
\text { the test parameters } \\
\text { on children }\end{array}$ & $\begin{array}{l}\text { Rectal manometry in its current format is designed to meet } \\
\text { the clinical assessment of adult patients. Detailed studies to } \\
\text { understand the usefulness of each of the manometry parameters } \\
\text { in pediatrics is an urgent priority }\end{array}$ \\
\hline ARM/HRAM & $\begin{array}{l}\text { Comparative studies between the two systems. A multicenter } \\
\text { study with standard protocol to minimize inter/intra-observer } \\
\text { variabilities }\end{array}$ \\
\hline $\begin{array}{l}\text { Water-perfused/solid- } \\
\text { state catheters }\end{array}$ & $\begin{array}{l}\text { Comparative studies to evaluate the practical value and utility of } \\
\text { each of the catheter types for clinical assessment }\end{array}$ \\
\hline $\begin{array}{l}\text { Bowel preparation/ } \\
\text { enema/no preparation }\end{array}$ & $\begin{array}{l}\text { Comparative studies to address the need for and effect of } \\
\text { preprocedural preparation }\end{array}$ \\
\hline $\begin{array}{l}\text { Standard analysis and } \\
\text { reporting tools }\end{array}$ & $\begin{array}{l}\text { A multicenter studies to evaluate inter/intra-observer variabilities } \\
\text { and propose standardized protocol. } \\
\text { A follow on study must be undertaken to ensure objectives were } \\
\text { met }\end{array}$ \\
\hline $\begin{array}{l}\text { Automated/manual } \\
\text { assessment }\end{array}$ & $\begin{array}{l}\text { A multicenter studies to evaluate inter/intra-observer variabilities } \\
\text { and propose a standardized protocol. } \\
\text { A follow on study must be undertaken to ensure objectives were met }\end{array}$ \\
\hline
\end{tabular}

as transanal irrigation which was recently approved by NICE (the National Institute for Health and Care Excellence) in the UK, TENS (transcutaneous electrical nerve stimulation), botulinum toxin, and biofeedback for the management of CC and FI in children, the use of HRAM with provide vital information in understanding anorectal physiology in subset of children with $\mathrm{CC}$ and $\mathrm{FI}$ and to aid the guide their management.

We acknowledge the limitation of the consensus, particularly in the methodology part, but considering the limited data in pediatric and the increasing uptake of the use of ARM/HRARM we aim to guide pediatrician toward standardization of practice and to encourage the uptake of newer technologies (Table 6).

\section{CONFLICT OF INTEREST}

No conflict of interest to disclose.

\section{AUTHOR CONTRIBUTION}

All authors must have made a significant intellectual contribution to the manuscript according to the criteria formulated by the International Committee of Medical Journal Editors.

\section{ORCID}

Eleni Athanasakos (iD https://orcid.org/0000-0001-9207-7379

Steve Perring (iD https://orcid.org/0000-0002-8217-3487

Mohamed Mutalib iD https://orcid.org/0000-0001-8869-9466

\section{REFERENCES}

1. Rajindrajith S, Devanarayana NM, Perera BJC, Benninga MA. Childhood constipation as an emerging public health problem. World J Gastroenterol. 2016;22(30):6864.
2. Van Den Berg MM, Benninga MA, Di Lorenzo C. Epidemiology of childhood constipation: a systematic review. Am J Gastroenterol. 2006;101(10):2401-2409

3. Mugie SM, Benninga MA, Di Lorenzo C. Epidemiology of constipation in children and adults: a systematic review Head of Department Paediatric Gastroenterology and Nutrition. Best Pract Res Clin Gastroenterol. 2011; 25: 3-18.

4. Boronat AC, Ferreira-MaiaAP, Matijasevich A, Wang YP. Epidemiology of functional gastrointestinal disorders in children and adolescents: a systematic review. World J Gastroenterol. 2017;23(21):3915

5. Mugie SM, Benninga MA, Di Lorenzo C. Epidemiology of constipation in children and adults: a systematic review. Best Pract Res Clin Gastroenterol. 2011; 25: 3-8.

6. Koppen IJN, Vriesman MH, Saps M, et al. Prevalence of functional defecation disorders in children: a systematic review and meta-analysis. J Pediatr. 2018;198:121-130.e6.

7. Sommers T, Corban C, Sengupta N, et al. Emergency department burden of constipation in the United States from 2006 to 2011. Am J Gastroenterol. 2015;110(4):572-579.

8. Wald A, Sigurdsson L. Quality of life in children and adults with constipation. Best Pract Res Clin Gastroenterol. 2011;25(1):19-27.

9. Youssef NN, Langseder AL, Verga BJ, Mones RL, Rosh JR. Chronic childhood constipation is associated with impaired quality of life: acase-controlled study. J Pediatr Gastroenterol Nutr. 2005;41(1):56-60

10. Wang $\mathrm{C}$, Shang $\mathrm{L}$, Zhang $\mathrm{Y}$, et al. Impact of functional constipation on health-related quality of life in preschool children and their families in Xi'an, China. PLoS ONE. 2013;8(10):e77273.

11. Tabbers MM, Dilorenzo C, Berger MY, et al. Evaluation and treatment of functional constipation in infants and children: evidence-based recommendations from ESPGHAN and NASPGHAN. J Pediatr Gastroenterol Nutr. 2014;58(2):265-281.

12. Health NCC for W and C. Constipation in children and young people : Constipation Child young people diagnosis Manag idiopathic Child constipation Prim Second care. 2010. https://doi.org/10.13140/ 2.1.3573.6003 
13. Muddasani S, Moe A, Semmelrock C, et al. physical therapy for fecal incontinence in children with pelvic floor dyssynergia. J Pediatr. 2017;190:74-78.

14. Rajindrajith S, Devanarayana NM, Benninga MA. Review article: faecal incontinence in children: epidemiology, pathophysiology, clinical evaluation and management. Aliment Pharmacol Ther. 2013;37(1):37-48.

15. Voskuijl WP, Heijmans J, Heijmans HSA, Taminiau JAJM, Benninga MA. Use of Rome II criteria in childhood defecation disorders: applicability in clinical and research practice. J Pediatr. 2004;145(2):213-217.

16. Bongers MEJ, Tabbers MM, Benninga MA. Functional nonretentive fecal incontinence in children. J Pediatr Gastroenterol Nutr. 2007;44(1):5-13.

17. Rao SSC, Patcharatrakul T. Diagnosis and treatment of dyssynergic defecation. J Neurogastroenterol Motil. 2016;22(3):423-435.

18. Rajindrajith S, Devanarayana NM, Benninga MA. Constipationassociated and nonretentive fecal incontinence in children and adolescents: an epidemiological survey in Sri Lanka. J Pediatr Gastroenterol Nutr. 2010;51(4):472-476.

19. Chumpitazi BP, Nurko S. Defecation disorders in children after surgery for hirschsprung disease. J Pediatr Gastroenterol Nutr. 2011;53(1):75-79.

20. Verhoef M, Lurvink M, Barf HA, et al. High prevalence of incontinence among young adults with spina bifida: description, prediction and problem perception. Spinal Cord. 2005;43(6):331-340.

21. Rao SSC, Azpiroz F, Diamant N, Enck P, Tougas G, Wald A. Minimum standards of anorectal manometry. Neurogastroenterol Motil. 2002;14(5):553-559.

22. Carrington EV, Brokjær A, Craven $\mathrm{H}$, et al. Traditional measures of normal anal sphincter function using high-resolution anorectal manometry (HRAM) in 115 healthy volunteers. Neurogastroenterol Motil. 2014;26(5):625-635.

23. Carrington EV, Heinrich $\mathrm{H}$, Knowles $\mathrm{CH}$, Rao SS, Fox M, Scott SM. Methods of anorectal manometry vary widely in clinical practice: results from an international survey. Neurogastroenterol Motil. 2017;29(8):e13016.

24. Dinning PG, Carrington EV, Scott SM. The use of colonic and anorectal high-resolution manometry and its place in clinical work and in research. Neurogastroenterol Motil. 2015;27(12):1693-1708.

25. Keshtgar AS, Athanasakos E, Clayden GS, Ward HC. Evaluation of outcome of anorectal anomaly in childhood: the role of anorectal manometry and endosonography. Pediatr Surg Int. 2008;24(8):885-892.

26. Keshtgar AS, Choudhry MS, Kufeji D, Ward HC, Clayden GS. Anorectal manometry with and without ketamine for evaluation of defecation disorders in children. J Pediatr Surg. 2015;50(3):438-443.

27. Rodriguez L, Sood M, Di Lorenzo C, Saps M. An ANMS-NASPGHAN consensus document on anorectal and colonic manometry in children. Neurogastroenterol Motil. 2017;29(1):e12944.

28. Morera C, Nurko S. Rectal manometry in patients with isolated sacral agenesis. J Pediatr Gastroenterol Nutr. 2003;37(1):47-52.

29. Molnar D, Taitz LS, Urwin OM, Wales JKH. Anorectal manometry results in defecation disorders. Arch Dis Child. 1983;58(4):257-261.

30. van Ginkel R, Büller HA, Boeckxstaens GE, van Der Plas RN, Taminiau JA, Benninga MA. The effect of anorectal manometry on the outcome of treatment in severe childhood constipation: a randomized, controlled trial. Pediatrics. 2001;108(1):e9-e9.

31. Noviello C, Cobellis G, Papparella A, Amici G, Martino A. Role of anorectal manometry in children with severe constipation. Color Dis. 2009;11(5):480-484.

32. De Lorijn F, Reitsma JB, Voskuijl WP, et al. Diagnosis of Hirschsprung's disease: a prospective, comparative accuracy study of common tests. J Pediatr. 2005;146(6):787-792.
33. Keshtgar AS, Ward HC, Clayden GS, De Sousa NM. Investigations for incontinence and constipation after surgery for Hirschsprung's disease in children. Pediatr Surg Int. 2003;19(1):4-8.

34. Ambartsumyan L, Rodriguez L, Morera C, Nurko S. Longitudinal and radial characteristics of intra-anal pressures in children using 3d high-definition anorectal manometry: new observations. Am J Gastroenterol. 2013;108(12):1918.

35. Tang YF, Chen JG, An HJ, et al. High-resolution anorectal manometry in newborns: normative values and diagnostic utility in Hirschsprung disease. Neurogastroenterol Motil. 2014;26(11):1565-1572.

36. Bredenoord AJ, Fox M, Kahrilas PJ, Pandolfino JE, Schwizer W, Smout AJPM. Chicago classification criteria of esophageal motility disorders defined in high resolution esophageal pressure topography. Neurogastroenterol Motil. 2012; 24: 57-65.

37. Ratuapli SK, Bharucha AE, Noelting J, Harvey DM, Zinsmeister AR. Phenotypic identification and classification of functional defecatory disorders using high-resolution anorectal manometry. Gastroenterology. 2013;144(2):314-322.e2.

38. de Lorijn F, Kremer LCM, Reitsma JB, Benninga MA. Diagnostic tests in hirschsprung disease. J Pediatr Gastroenterol Nutr. 2006;42(5):496-505.

39. Wu JF, Lu CH, Yang CH, Tsai IJ. Diagnostic role of anal sphincter relaxation integral in high-resolution anorectal manometry for hirschsprung disease in infants. J Pediatr. 2018;194:136-141.e2.

40. De Lorijn F, Kremer LCM, Reitsma JB, Benninga MA. Diagnostic tests in hirschsprung disease: a systematic review. J Pediatr Gastroenterol Nutr. 2006;42(5):496-505.

41. Rajindrajith S, Devanarayana NM. Constipation in children: novel insight into epidemiology, pathophysiology and management. J Neurogastroenterol Motil. 2011;17(1):35-47.

42. Keshtgar AS, Ward HC, Clayden GS. Pathophysiology of chronic childhood constipation: Functional and morphological evaluation by anorectal manometry and endosonography and colonic transit study. J Pediatr Surg. 2013;48(4):806-812.

43. LiuTT, Chen CL, YiCH. Anorectal manometry in patients with chronic constipation: a single-center experience. Hepatogastroenterology. 2008; 138: S-354.

44. Siddiqui A, Rosen R, Nurko S. Anorectal manometry may identify children with spinal cord lesions. J Pediatr Gastroenterol Nutr. 2011; 53(5): 507-511.

45. Hong J. Clinical applications of gastrointestinal manometry in children. Pediatr Gastroenterol Hepatol Nutr. 2014;17(1):23.

46. Di Lorenzo C, Hillemeier C, Hyman P, et al. Manometry studies in children: Minimum standards for procedures. Neurogastroenterol Motil. 2002;14(4):411-420.

47. Ciamarra P, Nurko S, Barksdale E, Fishman S, Di Lorenzo C. Internal anal sphincter achalasia in children: clinical characteristics and treatment with Clostridium botulinum toxin. J Pediatr Gastroenterol Nutr. 2003;37(3):315-319.

48. Belkind-Gerson J, Goldstein AM, Kuo B. Balloon expulsion test as a screen for outlet obstruction in children with chronic constipation. J Pediatr Gastroenterol Nutr. 2013;56(1):23-26.

49. Jarzebicka D, Sieczkowska J, Dadalski M, Kierkus J, Ryzko J, Oracz G. Evaluation of the effectiveness of biofeedback therapy for functional constipation in children. Turkish J Gastroenterol. 2016;27(5):433-438.

50. Wang Z, Hu L, Jin X, Li X, Xu L. Evaluation of postoperative anal functions using endoanal ultrasonography and anorectal manometry in children with congenital anorectal malformations. J Pediatr Surg. 2016;51(3):416-420.

51. Demirbag S, Tiryaki T, Purtuloglu T. Importance of anorectal manometry after definitive surgery for Hirschsprung's disease in children. African J Paediatr Surg. 2013;10(1):1. 
52. Tran K, Kuo B, Zibaitis A, Bhattacharya S, Cote C, Belkind-Gerson J. Effect of propofol on anal sphincter pressure during anorectal manometry. J Pediatr Gastroenterol Nutr. 2014;58(4):495-497.

53. Liu TT, Yi CH, Chen CL, Liu HT, Chen TY. Influence of intravenous propofol sedation on anorectal manometry in healthy adults. Am J Med Sci. 2009;337(6):429-431.

54. Pfefferkorn MD, Croffie JM, Corkins MR, Gupta SK, Fitzgerald JF. Impact of sedation and anesthesia on the rectoanal inhibitory reflex in children. J Pediatr Gastroenterol Nutr. 2004;38(3):324-327.

55. Eldridge $C$, Kennedy R. Nonpharmacologic techniques for distress reduction during emergency medical care: a review. Clin Pediatr Emerg Med. 2010;11(4):244-250.

56. Rawat D, Amon P, Mallon G, Berry F, Goto E. Using play specialist therapy to reduce the use of sedation for anorectal manometry tests. J Pediatr Gastroenterol Nutr. 2010; 50(Suppl 2).

57. Lamparyk K, Mahajan L, Debeljak A, Steffen R. Anxiety associated with high-resolution anorectal manometry in pediatric patients and parents. J Pediatr Gastroenterol Nutr. 2017;65(5):e98-e100.

58. Lamparyk K, Mahajan L, Lamparyk C, et al. Effects of a psychological preparation intervention on anxiety associated with pediatric anorectal manometry. Int J Pediatr. 2017;65(5):e98-e100.

59. Lee TH, Bharucha AE. How to perform and interpret a high-Resolution anorectal manometry test. J Neurogastroenterol Motil. 2015;22(1):46-59.

60. Li Y, Yang X, Xu C, Zhang Y, Zhang X. Normal values and pressure morphology for three-dimensional high-resolution anorectal manometry of asymptomatic adults: a study in 110 subjects. Int J Colorectal Dis. 2013;28(8):1161-1168.

61. Coss-Adame E, Rao SSC, Valestin J, Ali-Azamar A, Remes-Troche JM. Accuracy and reproducibility of high-definition anorectal manometry and pressure topography analyses in healthy subjects. Clin Gastroenterol Hepatol. 2015;13(6):1143-1150.e1.

62. Noelting J, Ratuapli SK, Bharucha AE, Harvey DM, Ravi K, Zinsmeister AR. Normal values for high-resolution anorectal manometry in healthy women: effects of age and significance of rectoanal gradient. Am J Gastroenterol. 2012;107(10):1530-1536.
63. Gundling F, Seidl H, Scalercio N, Schmidt T, Schepp W, Pehl C. Influence of gender and age on anorectal function: normal values from anorectal manometry in a large caucasian population. Digestion. 2010;81(4):207-213.

64. Carrington EV, Grossi U, Knowles CH, Scott SM. Normal values for high-resolution anorectal manometry: a time for consensus and collaboration. Neurogastroenterol Motil. 2014;26(9):1356-1357.

65. Kumar S, Ramadan S, Gupta V, Helmy S, Atta I, Alkholy A. Manometric tests of anorectal function in 90 healthy children: a clinical study from Kuwait. J Pediatr Surg. 2009;44(9):1786-1790.

66. Benninga MA, Wijers OB, van der Hoeven CW, et al. Manometry, profilometry, and endosonography: normal physiology and anatomy of the anal canal in healthy children. J Pediatr Gastroenterol Nutr. 1994;18(1):68-77.

67. Banasiuk M, Banaszkiewicz A, Dziekiewicz M, Załęski A, Albrecht P. Values from three-dimensional high-resolution anorectal manometry analysis of children without lower gastrointestinal symptoms. Clin Gastroenterol Hepatol. 2016;14(7):993-1000.e3.

68. Azpiroz F, Enck P, Whitehead WE. Anorectal functional testing: review of collective experience. Am J Gastroenterol. 2002;97(2):232-240.

69. Burleigh DE, D'Mello A. Neural and pharmacologic factors affecting motility of the internal anal sphincter. Gastroenterology. 1983; 137: 53-61.

How to cite this article: Athanasakos E, Cleeve S, Thapar N, et al. Anorectal manometry in children with defecation disorders BSPGHAN Motility Working Group consensus statement. Neurogastroenterol Motil. 2020;00:e13797. https ://doi.org/10.1111/nmo.13797 